\title{
Research on Different Applications of SMA in Seismic Resistance of Building Structures
}

\author{
Zhang Zhe 1,2,a $^{1}$ \\ ${ }^{1}$ College of Civil Engineering, Huaqiao University, Xiamen, China \\ 2 501, Unit 2, Building 7, Wenhuayuan, Economic Development Zone, Zhangjiakou City, Hebei 075000, China
}

\begin{abstract}
SMA(Shape memory alloys) are unique materials with many excellent properties, such as excellent wear resistance, corrosion resistance, high power/weight ratio and biocompatibility, high damping, shape memory effect, super elasticity, etc. In civil engineering, scientists try to use the advantages of SMA by making it into different components and they have already made some types of components that are SMA bracing, SMA constrains RC columns, SMA ring springs and base isolation bearing. All of these components can make contributions to seismic resistance, therefore, this article mainly focuses on the the contribution of SMA bracings and SMA constrains RC columns to the seismic resistance of the structure and the relationship between the improvement of their own performance and SMA.
\end{abstract}

\section{INTRODUCTION}

Earthquake is a kind of sudden, destructive and frequent natural disaster, whose most of the energy is consumed through the plastic deformation of the building structure, leading to the destruction of the building structure. China is located between the Pacific Rim Seismic Belt and the Eurasian Seismic Belt, the plate movement is frequent, is a typical earthquake-prone country.

Furthermore, studies have shown that the world has entered a period of high seismic activity. The traditional seismic technology thought takes resistance as the central idea, when the building appears crack, the building does not collapse to ensure the function and safety. Construction industry seismic target of China generally covers three target that were buildings in small earthquake is not damaged, buildings in middle earthquake can be repaired, buildings in big earthquake does not fall [1]. The traditional seismic method increases the seismic performance of the building structure by increasing the stiffness and strength of the building structure, but often leads to the increase of the overall cost of the building structure, the difficulty of construction, and the effect is not ideal. Therefore, structural designers no longer blindly pursue to increase the overall stiffness of the building structure, but through the use of some other means to increase the seismic performance of the building structure. For example, there have been many researches on the contribution of shape memory alloys to earthquake resistance, which will be discussed in detail below.

\section{OVERVIEW OF SMA}

\subsection{DEFINITION OF SMA}

SMA(Shape memory alloys) are unique materials that can deform and return to a predetermined shape when unloaded or heated, and have been discovered for nearly a hundred years[2]. In 1932, Swedish scientist Ölander first observed the phenomenon of martensite increasing and decreasing with temperature In Au-Cd alloy. Since then, researchers have successively found this phenomenon In $\mathrm{Cu}-\mathrm{Zn}$ alloy, $\mathrm{Cu}-\mathrm{Sn}$ alloy and $\mathrm{In}-\mathrm{Tl}$ alloy[3].

Nowadays, we have found that shape memory alloys have many excellent properties, such as excellent wear resistance, corrosion resistance, high power/weight ratio and biocompatibility, high damping, shape memory effect, super elasticity, etc.[4] In the field of civil engineering, we mainly use its high damping and super elasticity to weaken the influence of earthquake and improve the seismic capacity of building structures.

\subsection{APPLICATIONS OF SMA}

Scientists have long been studying the application of shape memory alloys in high-end and sophisticated fields. Now, SMA has been widely used in many aspects of our life. It is acknowledged that SMA is found in many important instruments in aerospace, automotive, and biomedical applications in Tab.1. 
Table1. Applications of SMA in different fields.

\begin{tabular}{|c|c|}
\hline Field & Application \\
\hline Aerospace & $\begin{array}{c}\text { Fuselage, wings, landing } \\
\text { gear, engine, etc.[5] }\end{array}$ \\
\hline Automotive & $\begin{array}{c}\text { Radiator, fan clutch, engine, } \\
\text { fuel system, piston ring, } \\
\text { supercharger, transmission } \\
\text { control, brake, bumper, } \\
\text { rearview mirror, airbag, } \\
\text { hood, etc.[6] }\end{array}$ \\
\hline \multirow{3}{*}{ Biomedical Application } & $\begin{array}{c}\text { Stent, orthodontic appliance, } \\
\text { medical catheter, endoscope, } \\
\text { laparoscope, file, surgical } \\
\text { thread, artificial bone, } \\
\text { artificial joint, artificial } \\
\text { organ, fixed splint heart } \\
\text { repair device, thrombosis } \\
\text { filter, artificial blood vessel, } \\
\text { etc.[7]-[10] }\end{array}$ \\
\hline
\end{tabular}

In particular, in the field of civil engineering, the two most famous applications of SMA in the field of architecture are the bell tower of the church of San Giorgio[11] in Italy and the roof of the church of San Francesco[12]. The bell tower of the San Giorgio church, which was severely damaged by an earthquake in October 1996, was repaired by connecting four pre-stretched steel rods with four hyperelastic SMA rods, which were inserted from the top to the bottom of the tower Fig.1. In June of the following year, another earthquake occurred in the area, and the repaired clock tower remained intact, providing the strongest evidence of the seismic performance of the hyperelastic SMAdamper.

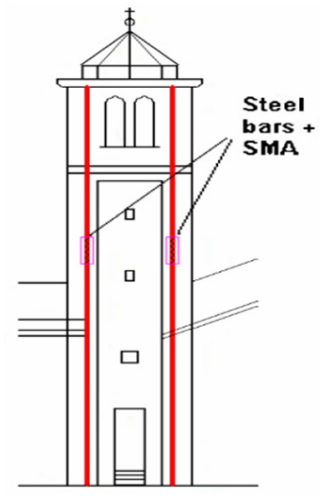

[11](a)Damping mounting position

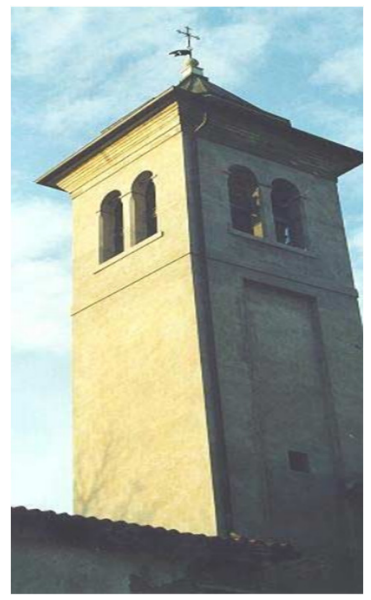

(b)The restored clock tower

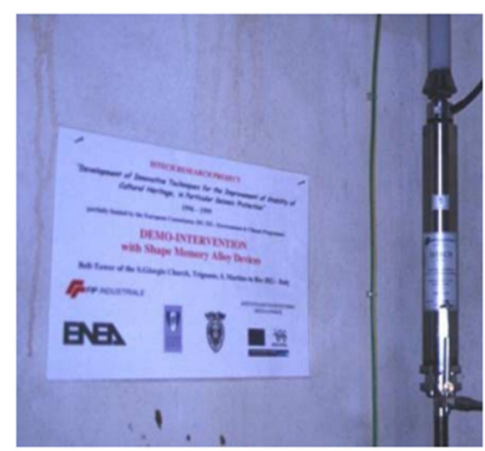

Figure 1. (c)Damper after installation

\section{SMA SEISMIC COMPONENT FORMS}

\subsection{SMA BRACINGS}

\subsubsection{DEFFERENT FORMS OF SMA BRACINGS}

Adding SMA bracings to the structure can improve the stiffness and damping ratio of the structure systems and reduce the seismic response. However, after adding SMA energy dissipation device, the reduction of structural response is not only related to the performance of the energy dissipation device itself, but also closely related to the arrangement of the energy dissipation device and its coordination with the structure. At present, the main forms of diagonal brace and chevron brace[13]. The deformation of this additional damper is less than or equal to the interlayer deformation of the structure. In the case of large structural deformation, the damper still cannot fully play its role. In order to increase the deformation of the damper and make it play a better role, some researchers put forward new energy dissipation bracings, such as scissors bracings and reverse bracings[14] Fig.2.
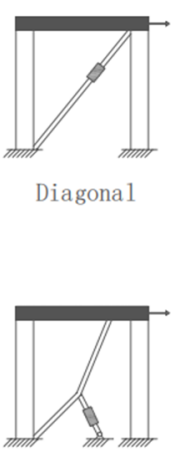

Lower toggle

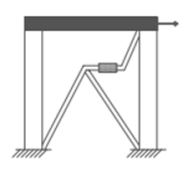

Chevron

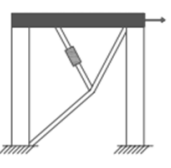

Upper toggle
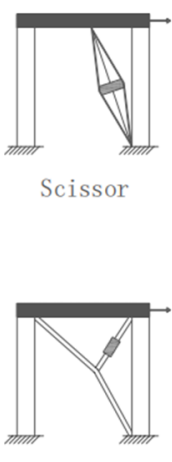

Reverse toggle
Figure 2. Different forms of bracings

\subsubsection{SINGLE DIAGONAL BRACING IS USED IN THE FRAME STRUCTURE}

Shi et al.[15] adopted the single diagonal bracing mode in their experiment and established the mode with OpenSees software, and achieved good experimental results. Therefore, we also adopted the experimental model in SHI 
and applied it to the experiment of $\mathrm{Hu}$ et al[16] for analysis Fig.3.

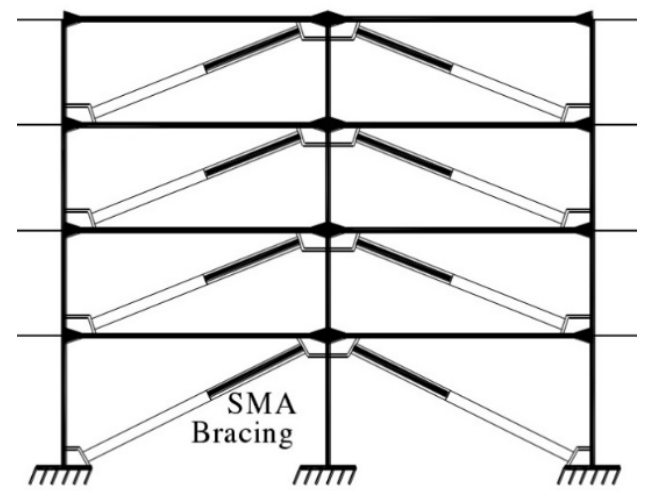

Figure 3. Single diagonal bracing in frame construction

\subsubsection{A TYPE OF STRUCTURE OF SMA BRACING}

Gu et al.[17] used a new self-reset SMA bracing which is consisted of the high-strength bolt(1), the subpanel(2), the sliding screw(3), SMA(4), the nut(5), the slip sheet(6), the left panel(7), the setting-up piece(8), the butyl rubber piece(9) and the right panel(10) Fig.4. A long round hole is respectively opened at the same position on the left and right sides of the middle of the front subpanel, the back subpanel and the right panel. The circular holes of bolts are respectively arranged on the same vertical axis of the front subpanel, the bank subpanel and the right panel. A butyl rubber gasket is arranged on both sides of each panel at the two long round holes, and then a slip gasket is arranged on the side far away from each panel of the butyl rubber gasket, and the front subpanel, the back subpanel and the right panel are fixed connected through the slip screw, and the slip screw is arranged in the long round hole near the end of the other side of the long round hole. The fixed gaskets are respectively arranged on both sides of each panel at the round hole of the bolt, and are fixed and connected by high strength bolts. After the bolts and screws are fixed, the SMA wire material is wound on the two sliding screws respectively to form the new self-reset SMA bracing.

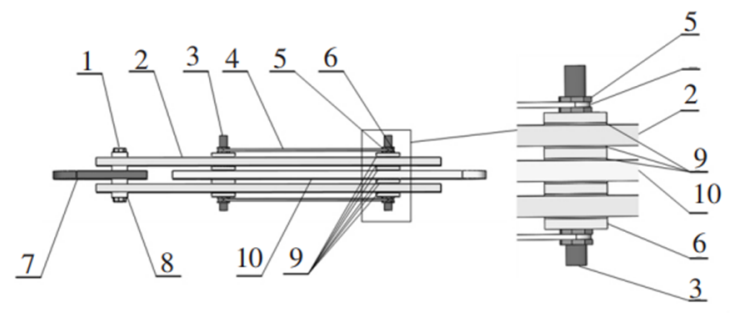

Figure 4. Structures of SMA bracing

\subsubsection{EXPERIMENTAL MODE AND DATA}

I extracted five groups of experiments from several groups of data in Hu's[16] experiment for analysis. The first group of tests was a bracing model without SMA wire as a control test. The second test was carried out with 16 laps of SMA wire (8 laps on each side) with a cross sectional area of $25.12 \mathrm{~mm}^{2}$ and a pretension of $1 \mathrm{KN}$. The third test was carried out with 28 laps of SMA wire (14 laps on each side) with a cross sectional area of $43.96 \mathrm{~mm}^{2}$ and a pretension of $1 \mathrm{KN}$. The fourth test was carried out with 28 laps of SMA wire (14 laps on each side) with a cross sectional area of $43.96 \mathrm{~mm}^{2}$ and a pretension of $3 \mathrm{KN}$. The fifth test was carried out with 28 laps of SMA wire (14 laps on each side) with a cross sectional area of 25.12 $\mathrm{mm}^{2}$ and a pretension of $5 \mathrm{KN}$. The influence of SMA cross-sectional area on the bracing performance can be obtained through the experiments of group 2 and 3 . The influence of SMA pretension on the bracing performance can be obtained through the experiments of group 3, 4 and 5 in Tab.2.

Table2. The experimental group

\begin{tabular}{|c|c|c|c|c|c|}
\hline Specimen number & 1 & 2 & 3 & 4 & 5 \\
\hline specimen name & SCB-0-0 & SCB-16-1 & SCB-28-1 & SCB-28-3 & SCB-28-5 \\
\hline SMA laps & 0 & 16 & 28 & 28 & 28 \\
\hline SMA proportion $/ \mathrm{mm}^{2}$ & 0 & 25.12 & 43.96 & 43.96 & 43.96 \\
\hline SMA pretension force/KN & 0 & 1 & 1 & 3 & 5 \\
\hline
\end{tabular}

\subsubsection{THE EFFECT OF SMA PROPORTION ON PERFORMANCE}

The comparison between test 2 and test 3 shows that increasing the SMA area can effectively improve the bearing capacity of the component and slightly reduce the residual deformation of the component. In addition, increasing the SMA area has no obvious effect on the antislip bearing capacity Fig.5.

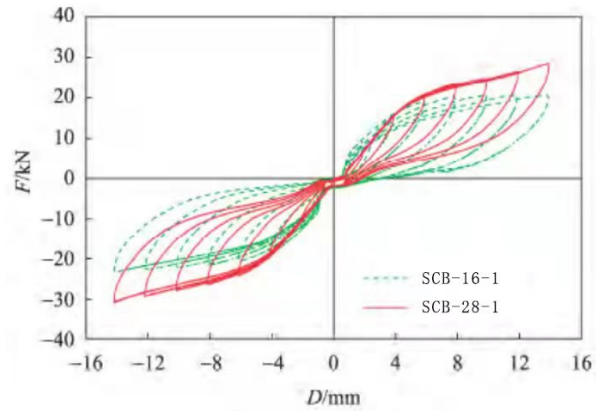

Figure 5. [18] effect of SMA proportion on performance

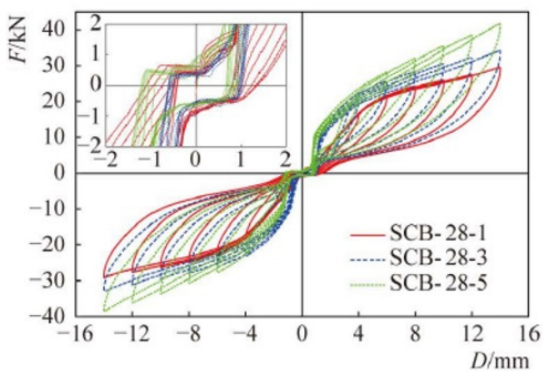

Figure 6. [16] effect of SMA pretension on performance

\subsubsection{EFFECT OF SMA PRETENSION ON PERFORMANCE}

Compared with the curves of $1 \mathrm{KN}, 3 \mathrm{KN}$ and $5 \mathrm{KN}$, it can be seen that increasing the SMA pretension can improve the bearing capacity of the component, but the hysteretic curve obtained is more kneaded and the hysteretic area is smaller, which is mainly because increasing the pretension can make the SMA have higher stress under the same displacement. However, it has no obvious influence on the resistance sliding bearing capacity and residual 
deformation (the residual deformation deviates when the prestress is $5 \mathrm{KN}$, but the positive and negative residual deformation are basically the same, which may be caused by construction errors), and it has a good restoration ability Fig.6.

\subsubsection{ENERGY-DISSIPATING CAPACITY}

The corresponding energy dissipation value gradually increases with the increase of the displacement of each specimen, that is, the specimen can provide stable energy dissipation capacity. In addition, by comparing the two groups of experiments, we can find that increasing the amount of SMA can effectively improve the energy consumption capacity. By comparing the tests of 3, 4 and 5 groups, it can be found that the increase of SMA pretension also contributes to the energy consumption Fig.7.

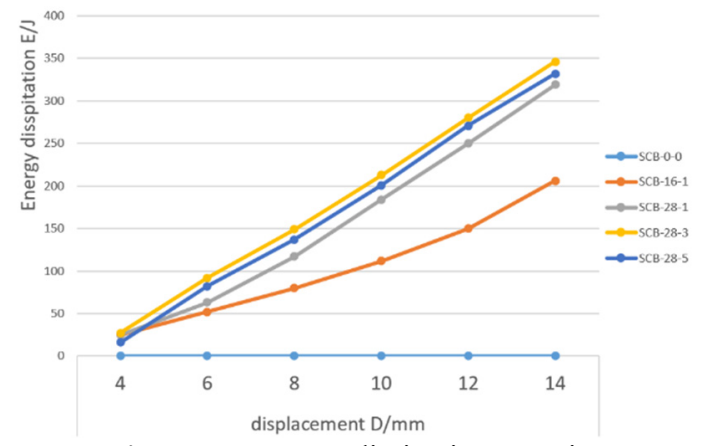

Figure 7. Energy-dissipating capacity

\subsection{SMA CONSTRAINS RC COLUMNS}

\subsubsection{EXPERIMENTAL DESIGN}

Pan[19] and Qian[20] have conducted relevant experiments in this regard. Both of them constrained RC columns with SMA wires, and used similar instruments to load the columns, observe and record the experimental situation. But there were some differences in their experiments such as the size of the columns and the reinforcement were not identical, though not identical. The restraint mode of SMA wire is different. Pan uses SMA wire to restrict the height of part of the column, while Qian is completely restricted by SMA wire from the bottom to the top of the column. Some detailed experiments are shown in Tab.3.

Table3. The experimental group

\begin{tabular}{|c|c|c|c|}
\hline & \multicolumn{3}{|c|}{ Pan $\quad$ Qian } \\
\hline Control group & SMA wire not & & \\
\hline Quantity of SMA & SMA winding is $300 \mathrm{~mm}$. the interal is $20 \mathrm{~mm}$ & In prestress is $2 \mathrm{KN}$ & 72 windings $s(c)$ \\
\hline Methods of reinforcement & 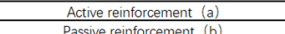 & 1 & \\
\hline & & & \\
\hline Prestress/KN & , & In 72 windings & $\frac{1(0)}{2(d)}$ \\
\hline
\end{tabular}

Figure 8 is a schematic diagram of the experimental instruments of Pan and Qian. The difference between the two has the column height is different, the SMA restraint range is different, the steel bar selection and the reinforcement is different. I will not study the experiment in detail, but specifically analyze the SMA wire constraints on the column energy consumption.

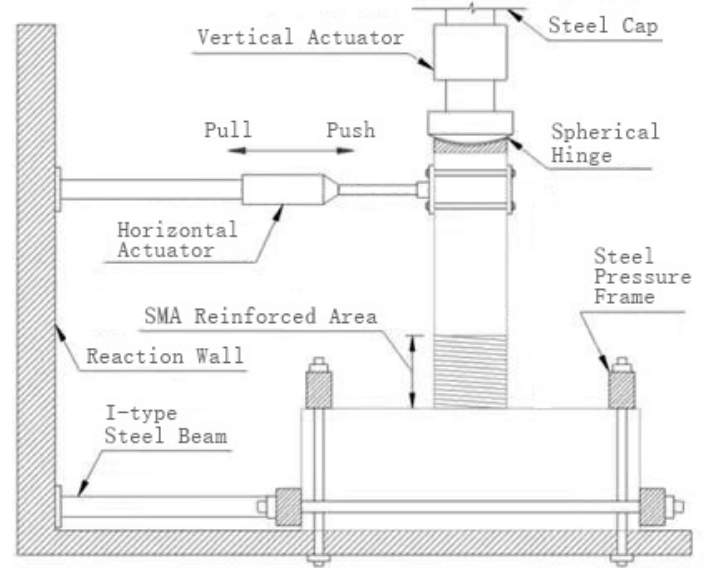

Figure 8. Experimental mode

\subsubsection{ENERGY-DISSIPATING CAPACITY}

I have summarized the experiments of Pan and Qian together and divided them into groups $0 \sim \mathrm{H}$, of which group 0 is the control experiment of A and B. As shown in Figure 9, each group respectively in the displacement of 5 $\mathrm{mm}, 10 \mathrm{~mm}, 15 \mathrm{~mm}, 20 \mathrm{~mm}, 25 \mathrm{~mm}, 30 \mathrm{~mm}, 35 \mathrm{~mm}$ and $40 \mathrm{~mm}$, reflected their energy consumption by intuition.

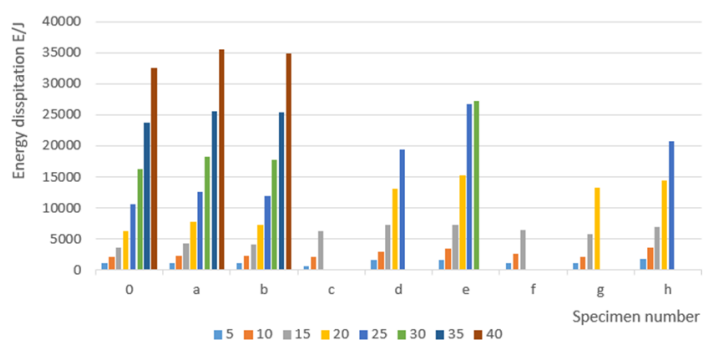

Figure 9. Energy-dissipating capacity

From the general point of view of the experiment of group $0 \sim \mathrm{H}$, although the experimental conditions and methods are not exactly the same, under the same displacement conditions, the amount of energy consumption is at the same order of magnitude and theoretically correct. Therefore, it is feasible and meaningful to compare them together. With the increase of SMA placement rate, the energy dissipation capacity of all the specimens increased, and with the increase of displacement, the energy dissipation capacity increased more obviously.

As can be seen from groups 0 , a and b in the figure, when the horizontal displacement reaches $10 \mathrm{~mm}$, the accumulated energy dissipation of the three specimens is almost the same, indicating that the energy dissipation of all specimens is basically the same before the occurrence of major oblique cracks. After $120 \mathrm{~mm}$, the accumulative energy consumption of the reinforcement pieces is higher than that of the original specimen. Moreover, when the horizontal displacement is $40 \mathrm{~mm}$, the accumulative energy consumption of the reinforcement pieces A and B is $3554 \mathrm{~J}$ and $34891 \mathrm{~J}$, respectively, which is increased by $9 \%$ and $7 \%$ compared with that of the original specimen 32609J. It can be found that under the same displacement amplitude, SMA wire has a certain increase in the energy 
dissipation of pier column, and it shows that the energy dissipation capacity of the active reinforcement test piece is better than that of the passive reinforcement test piece, but the degree of improvement is limited. This is because the current SMA wire winding distance is relatively large, which leads to the small confining pressure provided to pier concrete. Therefore, the influence of different SMA wire interval can be considered in subsequent studies.

From the F, G, D and H groups, the energy dissipation capacity of RC pier with non-prestressed SMA wire is weaker than that of the prestressed specimen, because the SMA wire in the prestressed specimen forms a lateral constraint on the RC pier earlier and participates in the energy dissipation of the specimen earlier. The energy dissipation capacity of SMA wire with pretension of $2 \%$ and $4 \%$ is stronger than that with pretension of $1 \%$, but the energy dissipation capacity of SMA wire with pretension of $4 \%$ is weaker than that of sample with pretension of $2 \%$. This is because the wire begins to harden when the SMA strain rate reaches $6 \%$.

\subsubsection{OTHER CAPACITIES}

In addition to the energy dissipation capacity, the SMA wire reinforcement has a more significant effect on the strength attenuation control of the pier under cyclic load, which improves the bearing capacity, ductility, stiffness degradation and residual deformation of the pier. I will not go into details here.

\subsection{OVERVIEW OF OTHER COMPONENT FORMS}

In addition to the above two SMA application methods, there are many other SMA components proposed by scholars, which can also improve the seismic performance of building structures.

SMA ring spring is a kind of efficient shock absorption functional element[21], which is composed of an interconnected SMA outer ring and an inner ring of fine steel. Deformation mainly concentrates on the outer ring of SMA, while the inner ring of fine steel remains elastic. SMA ring spring can change the axial (or bending) force mechanism into the circum-axial force mechanism with overload protection characteristics, which solves the problems of anchorage, fracture prevention and other aspects, and breaks through the problem of low utilization rate of SMA materials.

In addition, SMA components can also be installed in the beam-and-column joints to make the overall structure self-reset, ensuring that other important components (such as beams and columns) basically remain elastic under the action of the earthquake, so that the repair work and costs after the earthquake are minimized. At present, the research of SMA screw joint and SMA end-plate joint has attracted much attention. Sepulveda et al.[22] conducted experiments on the self-reset beam-and-column joints with copper-based SMA screws, and the results showed that the joints had certain hyperelastic behavior and energy dissipation capacity, and no performance degradation occurred within the displacement Angle of 3\%.
The base isolation bearing can effectively reduce the seismic response of multi-story buildings and Bridges, and the self-reset and energy dissipation capacity of the isolation bearing can be further improved by using SMA components. The isolation bearing based on SMA technology mainly has two types SMA- rubber bearing and SMA- friction bearing. For SMA-rubber bearing, the SMA wire (or stranded wire) is interspersed between the upper and lower end plates, and the stretching of the SMA wire is driven by the relative displacement of the upper and lower end plates. Dezfuli et al.[23] and Shinozuka et al.[24] concluded through finite element analysis that such bearings had superior self-reset performance and energy dissipation capacity. Gur et al.[25] studied the isolation effect of SMA-rubber bearing under near-fault earthquake action, and believed that SMA-rubber bearing has advantages over ordinary lead-rubber bearing in three indicators of acceleration, maximum structural displacement and residual displacement. Ozbulut et al.[26] considered the influence of outdoor temperature difference on SMA-friction bearing, and found that if $20^{\circ} \mathrm{C}$ was taken as the reference temperature, the influence of fluctuation of $20{ }^{\circ} \mathrm{C}$ on the maximum displacement of bearing was not more than $13 \%$, and the influence on acceleration was negligible at about $2 \%$.

\section{CONCLUSIONS}

There is no doubt that SMA has many unique advantages, and there is a lot of room to play in the seismic aspect of building structures. However, there are still many problems to be solved in the research and application of SMA. Firstly, the manufacturing cost needs to be reduced. At present, the SMA processing and preparation technology in the market are not mature, which not only causes its high cost, but also brings the material reliability problem, so it is still unable to realize the large-scale application of products[4]. In addition to this, steelconcrete composite structure is the main form of modern steel structure system, but there is little research on the performance of SMA composite joints and systems, and further consideration should be given to the deformation coordination of the structure and the damage of concrete floor. Also, the lack of research on the temperaturesensitive characteristics of SMA members and their effects on the seismic response of the whole structure is crucial to the development of the applicable conditions of SMA members including the range of indoor and outdoor working temperatures. From the perspective of energy consumption, whether the SMA component can be used as an energy consumption component alone is questionable, which needs to be analyzed from the aspects of functionality and economy. Besides, due to the degradation effect of SMA materials under large cyclic deformation, the post-disaster strengthening strategies and the ability to resist secondary disasters (such as aftershocks, etc.) of SMA systems have not been fully studied[27]. 


\section{REFERENCES}

1. Code for seismic design of buildings, vol. GB 500112. 2010 .

2. L. I. N. Cheng-xin and F. Wang, "Review of shape memory alloy application status NIU," J. TIANJIN Univ. Technol., vol. 36, no. 4, pp. 1-6, 2020.

3. J. Mohd Jani, M. Leary, A. Subic, and M. A. Gibson, "A review of shape memory alloy research, applications and opportunities," Mater. Des., vol. 56, pp. 1078-1113, 2014, doi: 10.1016/j.matdes.2013.11.084.

4. Y. Jiannan, "A Review of Shape Memory Alloys: Mechanical Behavior and Application," Chinese J. Solid Mech., 2021.

5. D. J. Hartl and D. C. Lagoudas, "Aerospace applications of shape memory alloys," Proc. Inst. Mech. Eng. Part G J. Aerosp. Eng., vol. 221, no. 4, pp. 535-552, 2007, doi: 10.1243/09544100JAERO211.

6. D. Stoeckel, "Shape Memory Actuators for Automotive Applications," Mater. Des., vol. 11, no. 6, pp. 302-307, 1991.

7. D. Mantovani, "Shape memory alloys: properties and biomedical applications," Jom, vol. 52, no. 10, pp. 36-44, 2000, doi: 10.1007/s11837-000-0082-4.

8. S. R. Oh et al., "A comparison of nickel-titanium rotary instruments manufactured using different methods and cross-sectional areas: ability to resist cyclic fatigue," Oral Surgery, Oral Med. Oral Pathol. Oral Radiol. Endodontology, vol. 109, no. 4, pp. 622628, 2010, doi: 10.1016/j.tripleo.2009.12.025.

9. R. Pfeifer, C. W. Müller, C. Hurschler, S. Kaierle, V. Wesling, and H. Haferkamp, "Adaptable orthopedic shape memory implants," Procedia CIRP, vol. 5, pp. 253-258, 2013, doi: 10.1016/j.procir.2013.01.050.

10. [10]G. Lim, K. Park, M. Sugihara, K. Minami, and M. Esashi, "Future of active catheters," Sensors Actuators, A Phys., vol. 56, no. 1-2, pp. 113-121, 1996, doi: 10.1016/0924-4247(96)01279-4.

11. M. Indirli, M. G. Castellano, P. Clemente, and A. Martelli, "Demo-application of Shape Memory Alloy devices:the rehabilitation of the S.Giorgio Church Bell-Tower," vol. 4330, pp. 262-272, 2001.

12. F. M. Mazzolani and A. Mandara, "Modern trends in the use of special metals for the improvement of historical and monumental structures," Eng. Struct., vol. 24, no. 7, pp. 843-856, 2002, doi: 10.1016/S0141-0296(02)00023-8.

13. Z. Deng, "New SMA Energy Dissipation Brace Systems," J. Beijing Univ. Technol., vol. 34, no. 5, pp. 511-515, 2008.

14. B. M. C. Constantinou, P. Tsopelas, A. Member, W. Hammel, A. N. Sigaher, and S. Member, "TOGGLEBRACE-DAMPER SEISMIC ENERGY DISSIPATION SYSTEMS By," no. February, pp. 105-112, 2001.
15. F. Shi, "Study on the Seismic Performance of Steel Frame Structure Equipped with Novel SMA Bracing System." .

16. S. J. Hu, Q. Gu, G. Q. Jiang, and J. G. Xiong, "Experimentral study on seimeic performance for an innovative self-centering sma brace," Gongcheng Lixue/Engineering Mech., vol. 38, no. 1, 2021, doi: 10.6052/j.issn.1000-4750.2020.02.0087.

17. G. U. Qi, S. Guquan, H. U. Shujun, G. U. O. Qi, and J. Jun, "Mechanical properties and design method of an innovative re- centering brace with low friction and SMA," 2019, doi: 10.13764/j.cnki.ncdg.2019.03.011.

18. S. Hu, Q. Gu, J. Jiang, G. Song, and J. Xiong, "Hysteresis performance and simplified mechanical model of an innovative self-centering SMA brace," Jianzhu Jiegou Xuebao/Journal Build. Struct., vol. 41, pp. 66-75, 2020, doi: 10.14006/j.jzjgxb.2020.S1.008.

19. S. Pan, R. Yue, H. Hui, and Y. Zhu, "Experimental Study on Seismic Performance of Active Confined RC Piers with NiTiNb-SMA Wires," Hunan Daxue Xuebao/Journal Hunan Univ. Nat. Sci., vol. 47, no. 7, pp. 93-101, 2020, doi: 10.16339/j.cnki.hdxbzkb.2020.07.011.

20. H. Qian, Z. Ren, J. Xiong, and L. Kang, "Experimental investigation on seismic performance of RC pier columns confined with shape memory alloy wires," Tumu Gongcheng Xuebao/China Civ. Eng. J., vol. 53, pp. 265-271, 2020, doi: 10.15951/j.tmgcxb.2020.s2.040.

21. C. Fang, M. C. H. Yam, A. C. C. Lam, and Y. Zhang, "Feasibility study of shape memory alloy ring spring systems for self-centring seismic resisting devices," Smart Mater. Struct., vol. 24, no. 7, p. 75024, 2015, doi: 10.1088/0964-1726/24/7/075024.

22. J. Sepúlveda, R. Boroschek, R. Herrera, O. Moroni, and M. Sarrazin, "Steel beam-column connection using copper-based shape memory alloy dampers," J. Constr. Steel Res., vol. 64, no. 4, pp. 429-435, 2008, doi: 10.1016/j.jcsr.2007.09.002.

23. F. Hedayati Dezfuli and M. S. Alam, "Performancebased assessment and design of FRP-based high damping rubber bearing incorporated with shape memory alloy wires," Eng. Struct., vol. 61, pp. 166183, 2014, doi: 10.1016/j.engstruct.2014.01.008.

24. M. Shinozuka, S. R. Chaudhuri, and S. K. Mishra, "Shape-Memory-Alloy supplemented Lead Rubber Bearing (SMA-LRB) for seismic isolation," Probabilistic Eng. Mech., vol. 41, pp. 34-45, 2015, doi: 10.1016/j.probengmech.2015.04.004.

25. and S. C. Sourav Gur, Sudib K. Mishra, "Performance assessment of buildings isolated by shape-memory- alloy rubber bearing: Comparison with elastomeric bearing under near-fault earthquakes," Struct. Control Heal. Monit., vol. 21, pp. 449-465, 2014, doi: 10.1002/stc.

26. O. E. Ozbulut and S. Hurlebaus, "Evaluation of the performance of a sliding-type base isolation system with a NiTi shape memory alloy device considering 
temperature effects," Eng. Struct., vol. 32, no. 1, pp. 238-249, 2010, doi: 10.1016/j.engstruct.2009.09.010.

27. C. Fang, W. Wang, and Y. Chen, "State-of-the-art for application of superelastic shape memory alloy in seismic resistant steel structures," Jianzhu Jiegou Xuebao/Journal Build. Struct., vol. 40, no. 7, pp. 112, 2019, doi: 10.14006/j.jzjgxb.2018.C168. 